\title{
Fracture mechanisms and fracture pattern in men and women aged 50 years and older: a study of a 12-year population-based injury register, Umeå, Sweden
}

\author{
U. Bergström • U. Björnstig • H. Stenlund • H. Jonsson • \\ O. Svensson
}

Published online: 10 May 2008

(C) International Osteoporosis Foundation and National Osteoporosis Foundation 2008

\section{Erratum to: Osteoporos Int}

DOI 10.1007/s00198-007-0549-z

Unfortunately an incorrect version of Fig. 1 was published, the principal error being that the two scales on the $y$-axis were transposed. The correct figure is presented here.

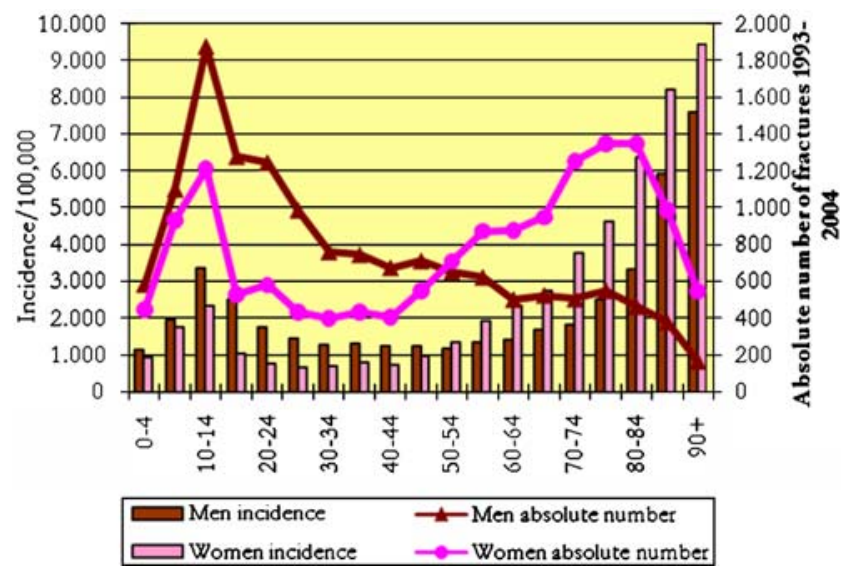

Fig. 1 Absolute numbers and incidence of fractures, 1993-2004

The online version of the original article can be found at http://dx.doi. org/10.1007/s00198-007-0549-z.

U. Bergström $(\bowtie) \cdot$ H. Jonsson $\cdot$ O. Svensson

Department of Orthopaedics, Umeå University Hospital,

Umeå, Sweden

e-mail: ulricabergstrom@hotmail.com

H. Stenlund

Department of Public health and Clinical Medicine,

Umeå University Hospital,

Umeå, Sweden

\section{U. Björnstig}

Division of Surgery and Perioperative Science,

Department of Orthopaedics, Umeå University Hospital,

90185 Umeå, Sweden 